RODRIGUES, Ricardo José Pereira. A adoção dos parâmetros da ocde para a regulamentação do lobby no brasil. Revista Eletrônica Direito e Política, Programa de Pós-Graduaç̧ão Stricto Sensu em Ciência Jurídica da UNIVALI, Itajaí, v.10, n.3, $2^{\circ}$ quadrimestre de 2015. Disponível em: www.univali.br/direitoepolitica - ISSN 1980-7791.

\title{
A ADOÇÃo DOS PARÂMETROS DA OCDE PARA A REGULAMENTAÇÃO DO LOBBY NO BRASIL ${ }^{1}$
}

\author{
ADOPTING OECD'S PARAMETERS FOR THE REGULATION OF \\ LOBBYING IN BRAZIL
}

Ricardo José Pereira Rodrigues ${ }^{2}$

SUMÁRIO: Introdução; 1 . O significado da regulamentação do lobby; 2. Arquitetura institucional da regulamentação do lobby; 2.1 Transparência; 2.2 Integridade; 2.3 Eficácia; Considerações finais; Referências das fontes citadas.

\section{RESUMO}

O presente artigo analisa as dificuldades de se regulamentar a atividade do lobby no contexto de democracias pluralistas e relata experiências internacionais, sobretudo dos Estados Unidos, com leis destinadas a normatizar as atividades de grupos de interesse e de lobistas. A partir da investigação de experiências internacionais, o artigo explora os princípios e os parâmetros que devem nortear a elaboração de normas para se regulamentar o lobby e aponta as limitações inerentes a esse tipo de regulamentação. O trabalho recorre metodologicamente à análise documental e à pesquisa bibliográfica para concluir que os parâmetros da transparência, da integridade e da eficácia são fundamentais para dar viabilidade à regulamentação do lobby.

PALAVRAS-CHAVE: Regulamentação do Lobby; Grupos de interesse; Transparência; Integridade; Eficácia.

\section{ABSTRACT}

This article analyzes the challenges of regulating lobbying in pluralistic democracies. It discusses comparative experiences with the formulation and enforcement of laws aimed at regulating the activities of pressure groups and

\footnotetext{
${ }^{1}$ Uma versão preliminar deste artigo foi apresentada em palestra proferida pelo autor na Controladoria Geral da União em 23 de setembro de 2014.

2 Doutor em Ciência Política pela State University of New York, Consultor Legislativa da Câmara dos Deputados e Professor de Ciência Política da Uniplan - DF. Email: ricardo.rodrigues@camara.leg.br
} 
RODRIGUES, Ricardo José Pereira. A adoção dos parâmetros da ocde para a regulamentação do lobby no brasil. Revista Eletrônica Direito e Política, Programa de Pós-Graduação Stricto Sensu em Ciência Jurídica da UNIVALI, Itajaí, v.10, n.3, 20 quadrimestre de 2015. Disponível em: www.univali.br/direitoepolitica - ISSN 1980-7791.

lobbyists, especially in the United States. Based on the analysis of such international experiences, the article advances principles and parameters which should guide the formulation of any legal framework to regulate lobbying and highlights the potential flaws of such laws. In terms of methodology, the paper resorts to bibliographical research and document analysis to conclude that transparency, integrity and compliance are essential parameters to make any regulation of lobbying viable.

Keywords: Lobbying regulation; Interest groups; transparency; Integrity; Compliance.

\section{INTRODUÇÃO}

A regulamentação do lobby tem se apresentado como um dos temas mais recorrentes na agenda de debates públicos do Brasil nas últimas três décadas. Frequentemente associado ao combate à corrupção, por um lado, e, por outro, visto como uma importante ferramenta para aprimorar a qualidade da democracia, a regulamentação do lobby tem ocupado espaço na mídia nacional e em simpósios que abordam os problemas políticos do país. Um exemplo é o recente artigo de Warde Júnior publicado no jornal Valor Econômico, no qual, ao analisar a questão das doações feitas por empresas para campanhas políticas, considera "indispensável uma adequada regulamentação do lobby" como parte da solução para conter o que ele chamou de "influência nefasta de organizações em busca de privilégios". ${ }^{3}$

A regulamentação do lobby também foi um dos assuntos mais discutidos durante

o Congresso Internacional de Legística que reuniu especialistas em Direito e Política de todo o mundo em Belo Horizonte, em 2007. Na ocasião, a Profa. Maria Coeli Simões Pires, por exemplo, defendeu que o país precisava "abrir a porta da frente" para o lobby. Para ela, a regulamentação do lobby permite que grupos e agentes do mercado não necessitem "de conluio e barganha para o

\footnotetext{
${ }^{3}$ WARDE JÚNIOR, Walfrido. Empresa não vota. Valor Econômico, 14 de maio de 2014, p. A12.
} 
RODRIGUES, Ricardo José Pereira. A adoção dos parâmetros da ocde para a regulamentação do lobby no brasil. Revista Eletrônica Direito e Política, Programa de Pós-Graduaç̧ão Stricto Sensu em Ciência Jurídica da UNIVALI, Itajaí, v.10, n.3, 20 quadrimestre de 2015. Disponível em: www.univali.br/direitoepolitica - ISSN 1980-7791.

acesso pelos porões da instituição (legislativa)". ${ }^{4}$ Tônica semelhante foi seguida por outra conferencista do evento para quem "a regulamentação do lobby representa uma possibilidade de grande potencial democrático, na medida em que os destinatários da norma têm condição de antecipar os problemas da nova legislação e se posicionar a seu respeito para a autoridade que está legislando". ${ }^{5}$

Entretanto, a despeito da recorrência do tema entre especialistas e da frequência com a qual ocupa espaço na mídia nacional, o Brasil não tem conseguido avançar nesta seara, transformando em norma jurídica os supostos anseios de se disciplinar a atividade do lobby. Por que a regulamentação do lobby tem se mostrado um objetivo tão difícil de atingir?

Certamente não tem sido por falta de interesse parlamentar no assunto. Esforços empreendidos no âmbito das duas Casas do Congresso Nacional datam do início da década de 1970. Em 1972, a Câmara dos Deputados apreciou o Projeto de Resolução no 38 que, entre outras alterações propostas ao Regimento Interno, previa o credenciamento de entidades de classe de empregados e empregadores, além de órgãos de profissionais liberais, para atuar legitimamente nas dependências da Casa como grupos de pressão. Aprovado pelos parlamentares, o projeto deu origem ao artigo 60 do Regimento Interno da Câmara à época, tornando-se o primeiro reconhecimento formal da presença de grupos de influência no Parlamento e da necessidade de regulamentar sua atuação. ${ }^{6}$

Em 1984, o então Senador Marco Maciel apresentou o Projeto de Lei do Senado no 25, que buscava disciplinar, de forma mais abrangente, a atuação dos grupos

\footnotetext{
${ }^{4}$ PIRES, Maria Coeli Simões. Diálogos e conflitos no processo de elaboração de leis. In: Legística: qualidade da lei e desenvolvimento. Belo Horizonte: Assembleia Legislativa do Estado de Minas Gerais, 2009, p. 143.

${ }^{5}$ SOARES, Fabiana de Menezes. Legística: história e objeto, fronteiras e perspectivas. In: Legística: qualidade da lei e desenvolvimento. Belo Horizonte: Assembleia Legislativa do Estado de Minas Gerais, 2009, p. 59.

${ }^{6}$ RODRIGUES, Ricardo J. P. A regulamentação do lobby no Brasil: leitura crítica de um projeto de lei. Revista de Administração Pública - RAP, Rio de Janeiro, vol. 30, n. 1, Janeiro/fevereiro, 1996, p. 55.
} 
RODRIGUES, Ricardo José Pereira. A adoção dos parâmetros da ocde para a regulamentação do lobby no brasil. Revista Eletrônica Direito e Política, Programa de Pós-Graduaç̧ão Stricto Sensu em Ciência Jurídica da UNIVALI, Itajaí, v.10, n.3, 20 quadrimestre de 2015. Disponível em: www.univali.br/direitoepolitica - ISSN 1980-7791.

de pressão no âmbito do Congresso Nacional. Inspirado na legislação norteamericana de 1946, o projeto do Senador Maciel objetivava dar mais transparência à atuação de grupos ou de indivíduos operadores do lobby no Poder Legislativo, tornando obrigatório o registro perante as Mesas Diretoras da Câmara e do Senado e o credenciamento que Ihes permitiria o acesso às Casas legislativas federais e que disciplinaria "o modo e limites (da) atuação" daquelas pessoas físicas e jurídicas.

Arquivada ao fim da legislatura, a proposição foi reapresentada em 1989, como Projeto de Lei do Senado no 203, com mínimas alterações. No Senado, a iniciativa do Senador Maciel recebeu parecer favorável, sendo encaminhada à Câmara e lá recebendo a rubrica de Projeto de Lei no 6.132-A, de 1990.

Na Câmara dos Deputados, a proposição do Senador Marco Maciel recebeu parecer favorável da Mesa Diretora. Porém, na Comissão de Constituição e Justiça, recebeu parecer pela inconstitucionalidade. Após aprovação de recurso de autoria do Deputado Paes Landim, a proposição foi encaminhada ao Plenário para apreciação, permanecendo em tramitação na Câmara dos Deputados até os dias de hoje.

De lá para cá, várias outras proposições que objetivavam a regulamentação do lobby tramitaram na Câmara dos Deputados e no Senado Federal, a maioria sob a forma de projetos de resolução. Atualmente, tramita na Câmara o Projeto de Lei no 1202-A, de 2007, de autoria do Deputado Carlos Zaratine, cujo teor apresenta-se mais abrangente do que a proposição original do Senador Marco Maciel. No Senado Federal, por sua vez, tramita o Projeto de Lei no 336, de 2015, de autoria do Senador Walter Pinheiro.

O presente trabalho busca estudar as razões pelas quais não se regulamenta o lobby no Brasil. Assim, o artigo tem como objetivo principal pesquisar os fatores que têm dificultado a adoção de uma regulamentação do lobby no Brasil, analisando as virtudes e as limitações das iniciativas legislativas apresentadas no 
RODRIGUES, Ricardo José Pereira. A adoção dos parâmetros da ocde para a regulamentação do lobby no brasil. Revista Eletrônica Direito e Política, Programa de Pós-Graduaç̧ão Stricto Sensu em Ciência Jurídica da UNIVALI, Itajaí, v.10, n.3, 20 quadrimestre de 2015. Disponível em: www.univali.br/direitoepolitica - ISSN 1980-7791.

país para regulamentar essa atividade tendente a influenciar as decisões governamentais.

Para operacionalizar a análise, o trabalho emprega os parâmetros propostos pela Organização para Cooperação e Desenvolvimento Econômico, OCDE, como modelos de regulamentação do lobby, e apresenta um estudo comparado de diversos países que normatizaram a atividade com resultados variados. A hipótese que permeia o presente estudo é a de que as proposições apresentadas sobre o assunto no país não se enquadram nos parâmetros formulados pela OCDE a partir de experiências internacionais nem encaminham alternativas que abranjam a complexidade, o número de atores e os elementos constitutivos da questão no âmbito estritamente nacional.

Do ponto de vista da metodologia, o artigo recorre à pesquisa bibliográfica e à análise documental para examinar a pertinência dos parâmetros da transparência, da integridade e da eficácia em experiências bem sucedidas na regulamentação do lobby de países selecionados e a viabilidade de sua adoção no caso brasileiro.

\section{O SIGNIFICADO DA REGULAMENTAÇÃO DO LOBBY}

De acordo com o Dicionário Parlamentar e Político, a palavra lobby "designa a atividade organizada, exercida por um grupo de interesses definidos, com o objetivo de ser ouvido pelo poder público, para lhe transmitir informações e obter de seus agentes determinada lei ou ato normativo, parecer, decisão ou atitude diante de um problema, interesse ou postulação concretos" (FARHAT, 1996, p. 607). A regulação do lobby trata, portanto, do disciplinamento dessa atividade organizada e de suas implicações para a formulação de políticas públicas e a tomada de decisões governamentais.

Contudo, regulamentar o lobby encerra desafios legislativos significativos. Não se trata apenas de restringir ou proibir a atividade dos grupos ou de lobistas 
RODRIGUES, Ricardo José Pereira. A adoção dos parâmetros da ocde para a regulamentação do lobby no brasil. Revista Eletrônica Direito e Política, Programa de Pós-Graduaç̧ão Stricto Sensu em Ciência Jurídica da UNIVALI, Itajaí, v.10, n.3, 20 quadrimestre de 2015. Disponível em: www.univali.br/direitoepolitica - ISSN 1980-7791.

individuais. Trata-se de viabilizar uma empreitada legiferante caracterizada por dois objetivos distintos que, para alguns, podem parecer contraditórios.

Por um lado, uma regulamentação do lobby deve necessariamente estimular e fortalecer a atuação dos grupos de interesse sem, por outro lado, permitir que tal atuação descambe para o tráfico de influência ou a corrupção, ambos, crimes já previstos pelo Código Penal Brasileiro.

O estímulo à atuação dos grupos deve-se ao caráter eminentemente pluralista do nosso modelo democrático. A teoria política concebe o pluralismo democrático como um modelo de democracia no qual grupos da sociedade civil se organizam e se mobilizam para defender mudanças no conjunto de políticas públicas em vigor. David $\operatorname{Truman}^{7}$ e Robert Dahl $^{8}$ postulavam que a mobilização de determinado interesse encorajaria a mobilização no sentido contrário de outros interesses até que todos os interesses afetados por uma política pública também se organizassem para a ação política. De acordo com Godwin, Ainsworth e Godwin, "uma vez que todos os interesses fossem mobilizados, um novo equilíbrio político resultaria". ${ }^{9}$

No Brasil, o pluralismo foi alçado à condição de princípio fundamental do nosso Estado democrático de direito. A Constituição Federal de 1988 consagra o pluralismo político, já no artigo 10 , inciso $\mathrm{V}$, como um dos fundamentos da democracia brasileira.

Ademais, historicamente, a atividade do lobby tem origem no direito de petição. Trata-se de um direito garantido na maioria das democracias. Kaiser ${ }^{10}$ lembra que a petição é um direito garantido pela Primeira Emenda da Constituição dos

\footnotetext{
7 TRUMAN, David. The Governmental process: political interests and public opinion. New York: Alfred Knopf, 1951.

${ }^{8}$ DAHL, Robert. Who governs? Democracy and power in an American city. New Haven: Yale University Press, 1961.

${ }^{9}$ GODWIN, Ken, AINSWORTH, Scott, GODWIN, Erik. Lobbying and policymaking: The public pursuit of private interests. Washington, D.C.: CQ Press, 2013, p. 26.

10 KAISER, Robert. So damn much money: the triumph of lobbying and the corrosion of American government. New York: Vintage, 2010, p. 94-95.
} 
RODRIGUES, Ricardo José Pereira. A adoção dos parâmetros da ocde para a regulamentação do lobby no brasil. Revista Eletrônica Direito e Política, Programa de Pós-Graduação Stricto Sensu em Ciência Jurídica da UNIVALI, Itajaí, v.10, n.3, 20 quadrimestre de 2015. Disponível em: www.univali.br/direitoepolitica - ISSN 1980-7791.

Estados Unidos e pela Common Law da Inglaterra. Segundo ele, na Inglaterra, o direito de petição surgiu no século treze e, ao longo dos séculos subsequentes, à medida que o Parlamento inglês foi se tornando mais democrático, "o direito de peticionar as autoridades evoluiu, tornando-se um pilar da constituição Inglesa não escrita". ${ }^{11}$ Para Lenza, o objetivo do direito de petição nada mais é do que, "em nítido exercício das prerrogativas democráticas, levar ao conhecimento do Poder Público a informação ou notícia de um ato ou fato ilegal, abusivo ou contra direitos, para que este tome as medidas necessárias". ${ }^{12}$

No Brasil, o direito de petição é garantido pela Constituição Federal de 1988 como um dos direitos e garantias fundamentais. $O$ inciso XXXIV do art. $5^{\circ}$. assegura aos brasileiros "o direito de petição aos poderes públicos em defesa de direitos ou contra ilegalidade ou abuso de poder" ${ }^{13}$ Esse direito é reiterado pela Constituição em seu art. $58, \S 2{ }^{\circ}$, inciso IV, quando determina às comissões das Casas do Congresso Nacional "receber petições, reclamações, representações ou queixas de qualquer pessoa contra atos ou omissões das autoridades ou entidades públicas". ${ }^{14}$

Cabe salientar que o lobby não é um fenômeno político unidimensional. De fato, a atividade apresenta uma diversidade de atores que, por sua vez, perseguem uma multiplicidade de objetivos. Pode-se enumerar pelo menos três tipos de lobby: o lobby de Advocacy, o lobby corporativista e o lobby empresarial.

O primeiro tipo de lobby refere-se às atividades tendentes a influenciar o processo de tomada de decisões governamentais realizadas por grupos organizados da sociedade civil, geralmente organizações não governamentais. Esses grupos são também chamados de grupos de ação cidadã (citizen action

${ }^{11}$ KAISER, Robert. So damn much money: the triumph of lobbying and the corrosion of American government, p. 96.

12 LENZA, Pedro. Dicionário constitucional esquematizado, 17a ed. São Paulo: Saraiva, 2013, p. 1073.

${ }^{13}$ BRASIL. Constituição da República Federativa do Brasil. Brasília: Edições Câmara, 2012 , p. 15.

14 BRASIL. Constituição da República Federativa do Brasil, p. 51. 
RODRIGUES, Ricardo José Pereira. A adoção dos parâmetros da ocde para a regulamentação do lobby no brasil. Revista Eletrônica Direito e Política, Programa de Pós-Graduação Stricto Sensu em Ciência Jurídica da UNIVALI, Itajaí, v.10, n.3, 20 quadrimestre de 2015. Disponível em: www.univali.br/direitoepolitica - ISSN 1980-7791.

groups). ${ }^{15}$ O grupo SOS Mata Atlântica, no Brasil, e o Sierra Club, nos Estados Unidos, constituem exemplos do lobby de advocacy dirigido exclusivamente à questão da defesa do meio-ambiente.

O lobby corporativista pode ser divido em patronal e de trabalhadores. Trata-se do lobby realizado pelas confederações nacional da indústria, da agricultura, do comércio e dos transportes, entre outras entidades patronais, e aquele realizado por centrais trabalhistas como a CUT, a Força Sindical, entre outras. Ambos buscam maximizar benefícios para suas respectivas categorias ou corporações.

Já o lobby empresarial diz respeito às atividades de empresas ou grupos de empresas tendentes a influenciar o processo de formulação de políticas públicas ou a tomada de decisão governamental. Além do processo legislativo, inclui-se entre os interesses do lobby empresarial o processo orçamentário e as decisões relativas a compras e aquisição de bens e serviços por órgãos governamentais.

Este tipo de lobby pode ser operacionalizado internamente ou por meio de contratação de terceiros. No primeiro caso, a própria empresa interessada em se engajar em atividades de lobby terá em sua folha de pagamentos empregados que farão o lobby como representantes diretos da empresa. No segundo caso, o lobby é realizado por "indivíduos que trabalham para firmas de lobby" sob contrato com empresas ou grupos de empresas. ${ }^{16}$

De uma forma geral, as leis que regulamentam o lobby mundo afora buscam disciplinar quase que exclusivamente a atuação do lobby empresarial, deixando de fora da regulamentação os demais tipos listados. Mas, até que ponto, esse foco no lobby empresarial não representa uma quebra de tratamento isonômico?

\footnotetext{
15 GODWIN, Ken, AINSWORTH, Scott, GODWIN, Erik. Lobbying and policymaking. The public pursuit of private interests, p. 94.

${ }^{16}$ GODWIN, Ken, AINSWORTH, Scott, GODWIN, Erik. Lobbying and policymaking. The public pursuit of private interests, p. 7.
} 
RODRIGUES, Ricardo José Pereira. A adoção dos parâmetros da ocde para a regulamentação do lobby no brasil. Revista Eletrônica Direito e Política, Programa de Pós-Graduaç̧ão Stricto Sensu em Ciência Jurídica da UNIVALI, Itajaí, v.10, n.3, 20 quadrimestre de 2015. Disponível em: www.univali.br/direitoepolitica - ISSN 1980-7791.

\section{ARQUITETURA INSTITUCIONAL DA REGULAMENTAÇÃO DO LOBBY}

Duas premissas devem nortear qualquer projeto de regulamentação das atividades do lobby. Em primeiro lugar, deve-se levar em consideração a diversidade de atores e tipos de lobby existentes. Em segundo, deve-se ter em mente que há diferentes loci institucionais a que se destinam as atividades de lobby.

No passado, as leis criadas para regulamentar a atividade enxergavam apenas o Parlamento como locus institucional a ser abordado por operadores de lobby. Esse foi o caso da Lei de Regulamentação do Lobby dos Estados Unidos, de 1946.

Aquele diploma legal basicamente requeria dos lobistas o registro perante a Secretaria-geral da Câmara de Representantes, exigia das pessoas engajadas no lobby a apresentação à Secretaria-geral da Câmara de uma declaração detalhada dos recursos recebidos e dos gastos feitos no desenrolar de suas atividades e, por fim, tornava tais informações públicas. ${ }^{17}$

O Projeto de Lei do Senado no 25, de 1984, do Senador Marco Maciel apresentava abordagem semelhante, replicando a maioria dos dispositivos encontrados na lei norte-americana.

Compreende-se que as primeiras leis de lobby nos Estados Unidos estabeleceram o Parlamento como locus das atividades de lobby porque a iniciativa legislativa naquele país sempre foi formalmente considerada uma prerrogativa exclusiva do Poder Legislativo. Contudo, mesmo à época em que a lei foi promulgada, o lobby nos Estados Unidos já acontecia também no âmbito dos demais poderes da República. O Presidente, por exemplo, tinha então, como tem até hoje, a prerrogativa de editar ordens executivas que, de forma semelhante às medidas

17 RODRIGUES, Ricardo J. P. A regulamentação do lobby no Brasil: leitura crítica de um projeto de lei, p. 57. 
RODRIGUES, Ricardo José Pereira. A adoção dos parâmetros da ocde para a regulamentação do lobby no brasil. Revista Eletrônica Direito e Política, Programa de Pós-Graduação Stricto Sensu em Ciência Jurídica da UNIVALI, Itajaí, v.10, n.3, 20 quadrimestre de 2015. Disponível em: www.univali.br/direitoepolitica - ISSN 1980-7791.

provisórias brasileiras, são iniciativas unilaterais com plena força de lei. ${ }^{18}$ Além disso, na qualidade de líder de seu partido, o Presidente dos Estados Unidos sempre lançou mão de sua base para apresentar proposições de interesse do Governo.

Vê-se, portanto, que o foco no Parlamento como locus exclusivo das atividades de lobby constituía uma deficiência da primeira lei de lobby norte-americana e de todas as legislações que ela veio influenciar no mundo. A legislação que atualmente regulamenta o lobby nos Estados Unidos, a chamada Lei da Liderança Honesta e do Governo Aberto, de 2007, reconheceu tal deficiência e procurou incluir todos os Poderes da República no disciplinamento das atividades de lobby. ${ }^{19}$ Alguns pesquisadores afirmam que as agências reguladoras também deveriam ser incluídas na regulação do lobby porque constituem, cada vez mais, instâncias de produção de políticas públicas que atraem a ação de grupos de interesse e de lobistas profissionais. ${ }^{20}$

Em síntese, a regulamentação do lobby deve considerar que as atividades inerentes ao lobby envolvem diversos atores cuja atuação é dirigida a diferentes pontos do processo de tomada de decisão governamental.

Com base na experiência internacional, a Organização para a Cooperação e o Desenvolvimento Econômico, OCDE, sugere que a transparência, a integridade e a eficácia são fatores que estimulam a adoção de leis do lobby bem como objetivos a serem alcançados pela regulação da atividade. ${ }^{21}$ Entretanto, uma análise apurada dessa mesma experiência internacional revela que esses elementos representam muito mais para o processo de formulação de uma

\footnotetext{
${ }^{18}$ Ver RODRIGUES, Ricardo J. P. The preeminence of politics: executive orders from Eisenhower to Clinton. New York: LFB publishers, 2007.

19 RODRIGUES, Ricardo J. P. Mudança e continuidade na regulamentação do lobby nos Estados Unidos. Revista de Informação Legislativa, Brasília, vol. 49, n. 196, outubro/dezembro, p. 83-93, 2012.

${ }^{20}$ GODWIN, Ken, AINSWORTH, Scott, GODWIN, Erik. Lobbying and policymaking. The public pursuit of private interests, p. 207.

${ }^{21}$ OCDE. Lobbyists, government and public trust. Vol. 1: increasing transparency through legislation. Paris: OCDE Publishing, 2009.
} 
RODRIGUES, Ricardo José Pereira. A adoção dos parâmetros da ocde para a regulamentação do lobby no brasil. Revista Eletrônica Direito e Política, Programa de Pós-Graduaç̧ão Stricto Sensu em Ciência Jurídica da UNIVALI, Itajaí, v.10, n.3, $2^{\circ}$ quadrimestre de 2015. Disponível em: www.univali.br/direitoepolitica - ISSN 1980-7791.

política de regulamentação do lobby. De fato, a transparência, a integridade e a eficácia constituem princípios básicos que fundamentam a regulação do lobby, dando-Ihe coerência e sustentação. Esses princípios interagem-se entre si, gerando uma dinâmica capaz de potencializar a efetividade e o alcance da regulamentação.

\subsection{Transparência}

Rosendorff afirma que a transparência é, hoje, se não um pré-requisito pelo menos um sinônimo de democracia. Nas palavras desse pesquisador, "a formulação de políticas deixa de ser responsiva à vontade do povo quando é realizada nos bastidores, longe dos holofotes do escrutínio público" (2004, p. 3). ${ }^{22}$ Como sintetiza Furnas, "a transparência não resolve tudo, mas faz o mercado de interesses concorrentes funcionar melhor e, ao assim fazer, ajuda a gerar incentivos para que os políticos promovam resultados que respondem aos apelos da população".

Para a OCDE, a transparência é o instrumento com o qual a regulação se compromete a "expor ao público os processes em operação quando decisões governamentais são tomadas". ${ }^{23}$ Constitui "um meio de assegurar ao público que as autoridades estão trabalhando honestamente, em prol dos melhores interesses da comunidade e um incentivo para aqueles que buscam benefícios públicos a obedecer às normas em vigor". ${ }^{24}$

As leis de lobby, em sua maioria, apresentam as seguintes exigências relativas à transparência: cadastro de lobistas, relatórios sobre gastos com a atividade de lobby, lista de interesses almejados, lista de contatos realizados, acesso público

\footnotetext{
22 ROSENDORFF, B. Peter. Democracy and the supply of transparency. Paper presented at the Annual Meeting of the International Studies Association, Montreal, March 17-21, 2004.

23 OCDE. Lobbyists, government and public trust. Vol. 1: increasing transparency through legislation, p. 46.

${ }^{24}$ OCDE. Lobbyists, government and public trust. Vol. 1: increasing transparency through legislation, p. 47.
} 
RODRIGUES, Ricardo José Pereira. A adoção dos parâmetros da ocde para a regulamentação do lobby no brasil. Revista Eletrônica Direito e Política, Programa de Pós-Graduação Stricto Sensu em Ciência Jurídica da UNIVALI, Itajaí, v.10, n.3, 20 quadrimestre de 2015. Disponível em: www.univali.br/direitoepolitica - ISSN 1980-7791.

a informações cadastradas. Em alguns casos, há sanções previstas para o não cumprimento das exigências relativas à transparência.

Com a transparência, a regulamentação do lobby dá conhecimento da intenção e dos beneficiários da atividade de lobby e permite a obtenção de dados para se aferir o impacto do lobby na decisão governamental e os pontos de tomada de decisão mais afetados.

\subsection{Integridade}

Segundo Ruth Grant, uma pessoa com integridade é aquela na qual se pode confiar que fará a "coisa certa mesmo quando isso resultará em custos para $\mathrm{si}^{2}{ }^{25}$ Para ela, entre os elementos da integridade estão a vontade e a habilidade de resistir a pressões para se corromper. Para que prevaleça, faz-se necessário "uma série de julgamentos cuidadosos acerca das possibilidades de se fazer o que é certo em determinadas situações assim como manter-se vigilante com respeito a relações que possam debilitar a integridade". ${ }^{26}$

Na regulação do lobby, o termo integridade é empregado para se referir ao comportamento esperado ou exigido dos destinatários da ação do lobby. Diz respeito a seguir uma conduta ética e resistir à influência de qualquer atividade ilícita da parte de operadores do lobby. A integridade mantém relação próxima com a transparência na medida em que a primeira somente pode ser aferida por meio da segunda.

Nos Estados Unidos, a aprovação da Lei da Liderança Honesta e do Governo Aberto, em 2007, sinalizou o reconhecimento do Parlamento e do Governo de que não bastava cadastrar e credenciar lobistas e exigir a transparência dos gastos com o lobby para ter eficácia no disciplinamento da atividade. Após meio

\footnotetext{
25 GRANT, Ruth W. Hypocrisy and integrity: Machiavelli, Rousseau, and the ethics of politics. Chicago: University of Chicago Press, 1997, p. 2.

${ }^{26}$ GRANT, Ruth W. Hypocrisy and integrity: Machiavelli, Rousseau, and the ethics of politics, $p$. 169.
} 
RODRIGUES, Ricardo José Pereira. A adoção dos parâmetros da ocde para a regulamentação do lobby no brasil. Revista Eletrônica Direito e Política, Programa de Pós-Graduaç̧ão Stricto Sensu em Ciência Jurídica da UNIVALI, Itajaí, v.10, n.3, 20 quadrimestre de 2015. Disponível em: www.univali.br/direitoepolitica - ISSN 1980-7791.

século de insistência em parâmetros que deixavam de fora da legislação do lobby o componente da integridade, a Lei de 2007 nasceu da constatação de que o país teria que regulamentar a conduta dos destinatários das atividades de lobby.

Entre outras inovações, a lei norte-americana de 2007 tornou obrigatória a apresentação de relatórios identificando doações a campanhas de candidatos a cargos federais, repassou ao Federal Election Commission (FEC) a responsabilidade de coletar informações fiscais acerca de candidatos e de doações recebidas para serem cruzadas com as informações constantes dos relatórios de indivíduos e organizações que realizam o lobby, obrigou o FEC a tornar público, via internet, toda informação referente a contribuições eleitorais oriundas do lobby e, por fim, proibiu parlamentares e autoridades do Poder Executivo de receber quaisquer presentes de lobistas.

Transparência e integridade terão pouca utilidade prática na aplicação de leis que regulamentam o lobby caso não venham acompanhados de dispositivos que garantam sua eficácia. Para Pross, "esforços destinados a garantir integridade dependem, sobretudo, de dispositivos voltados para assegurar o seu cumprimento". ${ }^{27}$

\subsection{Eficácia}

A regulamentação do lobby deve conter dispositivos que garantam sua aplicação. $\mathrm{Na}$ ausência de tais dispositivos, corre-se o risco de a legislação não vir a ser respeitada e, portanto, pouco influir para coibir atividades de lobby consideradas ilícitas. Dispositivos que garantam a aplicação da lei deve, por sua vez, conter sanções tanto para quem realiza o lobby quanto para quem é seu destinatário.

A lei norte-americana de 2007 serve como um bom exemplo de eficácia na regulamentação do lobby. Aquele diploma legal facilitou a aplicação das sanções nele previstas. Enquanto antes da aprovação da nova lei era difícil para o

\footnotetext{
${ }^{27}$ PROSS, A. P. Lobbying: models for regulation. OECD symposium on lobbying: enhancing
} transparency. Paris, June 7-8, 2007, p. 9. 
RODRIGUES, Ricardo José Pereira. A adoção dos parâmetros da ocde para a regulamentação do lobby no brasil. Revista Eletrônica Direito e Política, Programa de Pós-Graduaç̧ão Stricto Sensu em Ciência Jurídica da UNIVALI, Itajaí, v.10, n.3, 20 quadrimestre de 2015. Disponível em: www.univali.br/direitoepolitica - ISSN 1980-7791.

Ministério Público Federal dos Estados Unidos processar lobistas, a partir de 2007, a situação se reverteu. Em 2008, por exemplo, o Senado e a Câmara dos Representantes enviaram ao Ministério Público 418 casos para serem investigados. Em 2009, esse número subiu para 457 casos. $^{28}$

A experiência da Austrália com a regulamentação do lobby oferece-nos um exemplo negativo de eficácia. Em 1983, o país instituiu o registro de lobistas. Entretanto, em 1996 esse instituto foi abandonado porque, de acordo com analistas, a regulamentação simplesmente não funcionava. Para o Governo, a lei era inaplicável, para comentaristas na imprensa local, os dispositivos da lei eram repetidamente ignorados. Nas palavras de Pross, o registro Australiano simplesmente "deixou de ter um propósito útil". ${ }^{29}$

O caso do Art. 259 do regimento Interno da Câmara dos Deputados que institui o credenciamento de entidades para atuar nas dependências daquela Casa do Poder Legislativo é igualmente problemático. O dispositivo, que nasceu nos anos setenta e continua em vigor basicamente cria um registro de entidades que realizam o lobby no Parlamento brasileiro. Contudo, não há acesso público aos dados do cadastro, não há monitoramento nem há estrutura para a realização de qualquer tipo de monitoramento. Isto é, o dispositivo regimental da Câmara reconhece e legitima o lobby de entidades, mas não dá transparência, não aborda a questão da integridade nas relações entre autoridades e o lobby e nem introduz medidas que pudessem garantir a eficácia.

A experiência internacional com a regulação do lobby deixa claro que é necessário dar transparência às atividades do lobby, mas só transparência não resolve. A transparência deve ser acompanhada de integridade e a eficácia deve acompanhar ambos.

\footnotetext{
${ }^{28}$ RODRIGUES, Ricardo J. P. Mudança e continuidade na regulamentação do lobby nos Estados Unidos, p. 91.

${ }^{29}$ PROSS, A. P. Lobbying: models for regulation, p. 10.
} 
RODRIGUES, Ricardo José Pereira. A adoção dos parâmetros da ocde para a regulamentação do lobby no brasil. Revista Eletrônica Direito e Política, Programa de Pós-Graduaç̧ão Stricto Sensu em Ciência Jurídica da UNIVALI, Itajaí, v.10, n.3, 20 quadrimestre de 2015. Disponível em: www.univali.br/direitoepolitica - ISSN 1980-7791.

Quando não se tem estes três fatores atuando em conjunto a legislação torna-se inadequada. A Lei de Regulação do Lobby dos Estados Unidos de 1946 destacase como exemplo negativo. A legislação previa o registro de lobistas, mas não o monitoramento. Em 1991, o United States Government Accountability Office (GAO) realizou uma auditoria dirigida às atividades de lobby e averiguou que 10 mil lobistas dos 13,5 mil que constavam de um diretório nacional do lobby não estavam registrados. ${ }^{30}$ O resultado da auditoria contribuiu para se produzir uma nova lei de lobby, a Lei da Transparência do Lobby, de 1995.

\section{CONSIDERAÇÕES FINAIS}

Concebe-se a regulamentação do lobby como uma legislação que discipline tanto o comportamento ético de autoridades públicas quanto a conduta daqueles que buscam influenciar sua tomada de decisões. A transparência é o princípio empregado para dar viabilidade a essa regulamentação desde que acompanhada de instrumentos que garantam a eficácia da lei. Não há como garantir tal eficácia sem uma estrutura que possa monitorar, auditar e manter todo o sistema regulatório funcionando adequadamente.

Em realidade, mesmo com estrutura e instrumental de monitoramento, não há uma segurança de que uma lei de regulamentação do lobby possa, de forma autônoma, resolver todos os problemas relacionados às atividades do lobby junto ao setor público. Isoladamente, uma lei de lobby, por mais bem concebida que seja, pode fazer pouco.

A regulamentação do lobby deve integrar um grupo de leis e políticas públicas que, em seu conjunto, atuem em prol da qualidade da governança e do aprimoramento das relações entre Estado e sociedade. Como bem afirma Pross,

\footnotetext{
${ }^{30}$ UNITED STATES GOVERNMENT ACCOUNTABILITY OFFICE. 2010 Lobbying disclosure: observations on lobbyists' compliance with disclosure requirements. Washington: GAO, April, 2011.
} 
RODRIGUES, Ricardo José Pereira. A adoção dos parâmetros da ocde para a regulamentação do lobby no brasil. Revista Eletrônica Direito e Política, Programa de Pós-Graduaç̧ão Stricto Sensu em Ciência Jurídica da UNIVALI, Itajaí, v.10, n.3, 20 quadrimestre de 2015. Disponível em: www.univali.br/direitoepolitica - ISSN 1980-7791.

ela deve ser "parte de um complexo regime regulatório, afetando e sendo afetada pelos demais elementos desse regime". ${ }^{31}$

Assim, a eficácia da regulamentação do lobby está diretamente vinculada à sua inter-relação com outros diplomas legais que disciplinam assuntos conexos ou transversais à questão do lobby. Nesse sentido, pode-se dizer que a força da regulação está na soma das diversas normas jurídicas que, tratando de aspectos distintos da governança, contribuem para a construção de um arcabouço legal tão abrangente quanto eficaz.

No Brasil, embora não haja perspectiva concreta de aprovação dos projetos sobre o lobby que tramitam no Congresso Nacional, pode-se dizer que a construção de um sistema regulatório propício ao disciplinamento do lobby já teve início. Três leis recentemente aprovadas no país dão fundamento a esta afirmação. Refiro-me à Lei no 12.527, de 2011, a chamada Lei de Acesso à Informação, a Lei no 12.846, de 2013, conhecida como a lei da empresa limpa, e a Lei no 12.813, também de 2013, que trata do problema do conflito de interesses de servidores públicos no âmbito do Poder Executivo.

${ }^{31}$ PROSS, A. P. Lobbying: models for regulation, p. 37. 
RODRIGUES, Ricardo José Pereira. A adoção dos parâmetros da ocde para a regulamentação do lobby no brasil. Revista Eletrônica Direito e Política, Programa de Pós-Graduação Stricto Sensu em Ciência Jurídica da UNIVALI, Itajaí, v.10, n.3, $2^{\circ}$ quadrimestre de 2015. Disponível em: www.univali.br/direitoepolitica - ISSN 1980-7791.

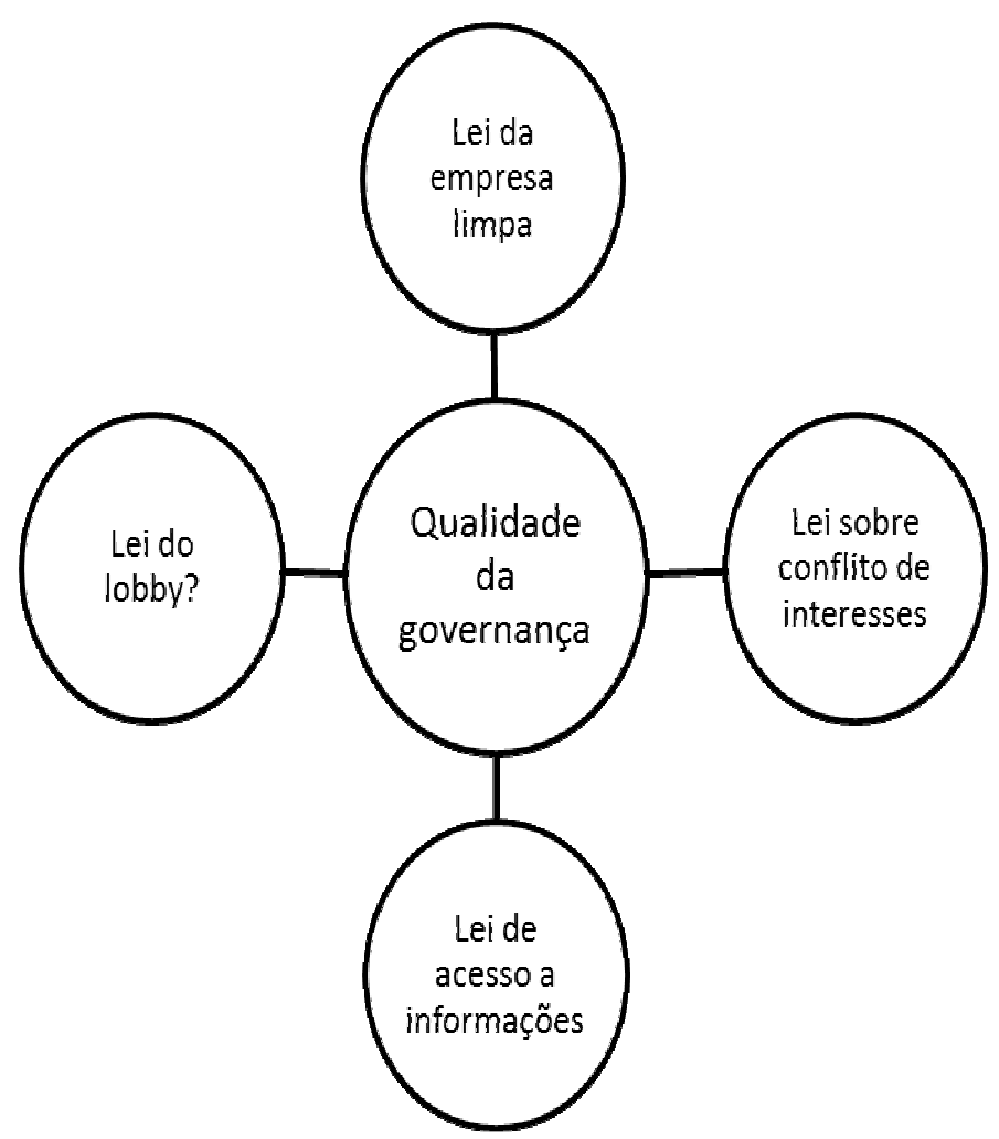

Figura 1. Diagrama de regime regulatório propício ao disciplinamento do lobby

A Lei de Acesso à Informação estabelece as diretrizes e os deveres que devem ser observados por órgãos públicos quanto à disponibilização de informações sob sua guarda. Entre os princípios que se destacam na lei está a garantia da publicidade, ou seja, da transparência, como regra geral e do sigilo como exceção para a administração pública. De fato, a lei faz da transparência não apenas um preceito a ser observado, mas, sobretudo, uma cultura a ser fomentada no âmbito dos três poderes da União.

Atualmente, a Lei de Acesso à Informação vem sendo subutilizada, inclusive pelos meios de comunicação de massa que têm concentrado muito mais seu foco nos salários de servidores públicos do que na integridade da gestão pública. Contudo, essa lei tem potencial para se tornar um pilar da boa governança democrática no país. Como afirmou Mendel, em entrevista ao jornal O Estado de 
RODRIGUES, Ricardo José Pereira. A adoção dos parâmetros da ocde para a regulamentação do lobby no brasil. Revista Eletrônica Direito e Política, Programa de Pós-Graduação Stricto Sensu em Ciência Jurídica da UNIVALI, Itajaí, v.10, n.3, $2^{\circ}$ quadrimestre de 2015. Disponível em: www.univali.br/direitoepolitica - ISSN 1980-7791.

São Paulo, "A lei de acesso a informações deu à população uma ferramenta poderosa de combate aos corruptos, aos desonestos, aos que enganam o público". 32

Já a Lei no 12.846, de 2013, a lei da empresa limpa, veio responsabilizar civil e administrativamente pessoas jurídicas pela prática de atos contra a administração pública. Como explica Carvalhosa, a lei parte do pressuposto de que as empresas que têm uma relação contratual com a União, os Estados e os municípios não são necessariamente vítimas indefesas de situações motivadas por interações com agentes públicos corruptos. Assim, reiterando uma tendência internacional em vigor, a lei torna as empresas "responsáveis por atos de corrupção, independentemente das pessoas físicas envolvidas". ${ }^{33}$

O art. $6^{\circ}$ da lei prevê multa que varia de $0,1 \%$ a $20 \%$ do faturamento bruto da empresa no exercício anterior ao da instauração do processo administrativo. A aplicação da multa, contudo, não afasta a "responsabilização, na esfera civil, dos agentes de tais atos de corrupção, a qual poderá resultar em perdimento dos bens, suspensão ou interdição parcial de atividades, dissolução compulsória da pessoa jurídica, proibição de receber incentivos, subsídios, doações ou empréstimos de órgãos ou entidades públicos". ${ }^{34}$

Por fim, a lei prevê acordos de leniência, baseado na autodelação. Para Carvalhosa, trata-se de importante instrumento de combate à corrupção. Segundo aquele autor, "ao assumir oficialmente a prática dos referidos atos de corrupção, fornecendo uma série de documentos e informações que comprovem a ocorrência de tais atos, a companhia envolvida delatora municiará as autoridades públicas com um dossiê completo que, no futuro, poderá ser

\footnotetext{
32 MENDEL, Toby. Toby Mendel, especialista em governo aberto, avalia lei brasileira de acesso a dados. O Estado de São Paulo, 29 de março de 2012. Disponível em: http://blogs.estadao.com.br/publicos/toby-mendel-especialista-em-governo-aberto-avalia-leibrasileira-de-acesso-a-dados/. Acesso em: 28/10/2014.

${ }^{33}$ CARVAlHOSA, Modesto. A nova lei da empresa limpa. O Estado de São Paulo, 30 de janeiro de 2014. Disponível em: http://opiniao.estadao.com.br/noticias/geral,a-nova-lei-da-empresalimpa-imp-,1124715. Acesso em: 28/10/2014.

${ }^{34}$ CARVALHOSA, Modesto. A nova lei da empresa limpa.
} 
RODRIGUES, Ricardo José Pereira. A adoção dos parâmetros da ocde para a regulamentação do lobby no brasil. Revista Eletrônica Direito e Política, Programa de Pós-Graduaç̧ão Stricto Sensu em Ciência Jurídica da UNIVALI, Itajaí, v.10, n.3, $2^{\circ}$ quadrimestre de 2015. Disponível em: www.univali.br/direitoepolitica - ISSN 1980-7791.

utilizado, judicialmente, nas esferas civil e penal, em face da própria companhia". 35

A Lei no 12.813, de 2013, por sua vez, disciplina situações que possam configurar conflito de interesses envolvendo ocupantes de cargo ou emprego no âmbito do Poder Executivo Federal. A norma atinge desde o Presidente da República e ministros de Estado até ocupantes de cargos de direção e assessoramento.

O texto legal considera como conflito de interesses no exercício do cargo uma série de situações que incluem a divulgação ou uso de informação privilegiada, seja em proveito próprio ou de terceiro, o exercício de atividade incompatível com as atribuições do cargo e a atuação, mesmo que informal, como intermediário de interesses privados em órgãos públicos de qualquer dos Poderes da União, dos Estados, do Distrito Federal e dos municípios. Ainda se considera conflito de interesses o recebimento de presente por agente público de quem tenha interesse em decisão deste agente ou de colegiado do qual participe, fora de limites e condições estabelecidos em regulamento.

A lei se aplica aos agentes públicos mesmo após deixarem seus respectivos cargos por um prazo de seis meses. Durante este período, os ex-servidores ficam proibidos de trabalhar com quem estabeleceu relacionamento enquanto exercia cargo federal, de aceitar cargo em área correspondente à vaga de quando era servidor, de celebrar contratos com o Poder Executivo e de intervir em favor de interesse privado junto ao órgão no qual atuou.

Juntos, esses diplomas legais constituem uma sinalização clara de que o caminho para a aprovação de uma lei de lobby eficaz está devidamente pavimentado. Quanto tempo ainda levará para a promulgação de uma regulamentação do lobby no país ainda é uma incógnita. Mas, pelo menos, o surgimento de tal regulamentação não se dará em meio a um vácuo de natureza legislativa. Uma

${ }^{35}$ CARVAlHOSA, Modesto. A nova lei da empresa limpa. 
RODRIGUES, Ricardo José Pereira. A adoção dos parâmetros da ocde para a regulamentação do lobby no brasil. Revista Eletrônica Direito e Política, Programa de Pós-Graduaç̧ão Stricto Sensu em Ciência Jurídica da UNIVALI, Itajaí, v.10, n.3, $2^{\circ}$ quadrimestre de 2015. Disponível em: www.univali.br/direitoepolitica - ISSN 1980-7791.

vez aprovada, a lei de lobby se somará às três normas acima citadas para formar um sistema regulatório de combate à corrupção e de disciplinamento das relações entre Estado e sociedade que poderá contribuir para o fortalecimento da governança democrática no Brasil.

\section{REFERÊNCIAS DAS FONTES CITADAS}

BRASIL. Constituição da República Federativa do Brasil. Brasília: Edições Câmara, 2012.

CARVAlhosA, Modesto. A nova lei da empresa limpa. O Estado de São Paulo, 30 de janeiro de 2014. Disponível em:

http://opiniao.estadao.com.br/noticias/geral,a-nova-lei-da-empresa-limpa-imp1124715. Acesso em: 28/10/2014.

CHARI, Raj, MURPHY, Gary, HOGAN, John. Regulating lobbyists: a comparative analysis of the United States, Canada, Germany and the European Union. The Political Quarterly, Londres, vol. 78, n. 3, p. 422-438, july-september, 2007.

DAHL, Robert. Who governs? Democracy and power in an American city. New Haven: Yale University Press, 1961.

FARHAT, Saïd. Dicionário parlamentar e político: o processo político e legislativo no Brasil. São Paulo: Editora Fundação Peirópolis: Companhia Melhoramentos, 1996.

FURNAS, Alexander. Why representative democracies can't write off transparency. The Atlantic, January 16, 2014. Disponível em: http://www.theatlantic.com/politics/print/2014/01/why-representativedemocracies-cant-write-off-transparency/283143/. Acesso em: 29/10/2014. 
RODRIGUES, Ricardo José Pereira. A adoção dos parâmetros da ocde para a regulamentação do lobby no brasil. Revista Eletrônica Direito e Política, Programa de Pós-Graduaç̧ão Stricto Sensu em Ciência Jurídica da UNIVALI, Itajaí, v.10, n.3, $2^{\circ}$ quadrimestre de 2015. Disponível em: www.univali.br/direitoepolitica - ISSN 1980-7791.

GODWIN, Ken, AINSWORTH, Scott, GODWIN, Erik. Lobbying and policymaking. The public pursuit of private interests. Washington, D.C.: CQ Press, 2013.

GRANT, Ruth W. Hypocrisy and integrity: Machiavelli, Rousseau, and the ethics of politics. Chicago: University of Chicago Press, 1997.

KAISER, Robert. So damn much money: the triumph of lobbying and the corrosion of American government. New York: Vintage, 2010.

LENZA, Pedro. Dicionário constitucional esquematizado, 17a ed. São Paulo: Saraiva, 2013.

MENDEL, Toby. Toby Mendel, especialista em governo aberto, avalia lei brasileira de acesso a dados. O Estado de São Paulo, 29 de março de 2012. Disponível em: http://blogs.estadao.com.br/publicos/toby-mendel-especialistaem-governo-aberto-avalia-lei-brasileira-de-acesso-a-dados/. Acesso em: 28/10/2014.

OCDE. Lobbyists, government and public trust. Vol. 1: increasing transparency through legislation. Paris: OCDE Publishing, 2009.

PIRES, Maria Coeli Simões. Diálogos e conflitos no processo de elaboração de leis. In: Legística: qualidade da lei e desenvolvimento. Belo Horizonte: Assembleia Legislativa do Estado de Minas Gerais, 2009, p. 119-156.

PROSS, A. P. Lobbying: models for regulation. OECD symposium on lobbying: enhancing transparency. Paris, June 7-8, 2007.

RODRIGUES, Ricardo J. P. A regulamentação do lobby no Brasil: leitura crítica de um projeto de lei. Revista de Administração Pública - RAP, Rio de Janeiro, vol. 30, n. 1, Janeiro/fevereiro, p. 55-63, 1996. 
RODRIGUES, Ricardo José Pereira. A adoção dos parâmetros da ocde para a regulamentação do lobby no brasil. Revista Eletrônica Direito e Política, Programa de Pós-Graduaç̧ão Stricto Sensu em Ciência Jurídica da UNIVALI, Itajaí, v.10, n.3, $2^{\circ}$ quadrimestre de 2015. Disponível em: www.univali.br/direitoepolitica - ISSN 1980-7791.

The preeminence of politics: executive orders from Eisenhower to Clinton. New York: LFB publishers, 2007.

Mudança e continuidade na regulamentação do lobby nos

Estados Unidos. Revista de Informação Legislativa, Brasília, vol. 49, n. 196, outubro/dezembro, p. 83-93, 2012.

ROSENDORFF, B. Peter. Democracy and the supply of transparency. Paper presented at the Annual Meeting of the International Studies Association, Montreal, March 17-21, 2004.

SOARES, Fabiana de Menezes. Legística: história e objeto, fronteiras e perspectivas. In: Legística: qualidade da lei e desenvolvimento. Belo Horizonte: Assembleia Legislativa do Estado de Minas Gerais, p. 55-68, 2009.

TRUMAN, David. The Governmental process: political interests and public opinion. New York: Alfred Knopf, 1951.

UNITED STATES GOVERNMENT ACCOUNTABILITY OFFICE. $\mathbf{2 0 1 0}$ Lobbying disclosure: observations on lobbyists' compliance with disclosure requirements. Washington: GAO, April, 2011.

WARDE JÚNIOR, Walfrido. Empresa não vota. Valor Econômico, São Paulo, 14 de maio de 2014, p. A12.

Submetido em: Junho/2015

Aprovado em: Julho/2015 